\title{
What birthdays should be celebrated?
}

\author{
Nature is planning to celebrate its 125th anniversary this year with a series of events that may reinforce its \\ international and public reputation.
}

$N_{A T U R E}$ will be 125 years old on 4 November this year and plans to mark the occasion in several ways but with appropriate diffidence. As our regular (and self-styled) anniversarists imply in the very last paragraph of their article on page 11, a 125th anniversary (which so obviously almost escapes their attention) is not calculated to excite the imagination generally, as do anniversaries whose ordinal numbers are divisible by one hundred. But that is too narrowly based a proposition. In earlier times, the magic number might just as well have been 7,13 or any other integer, suggesting that Nature's way out of this dilemma would be to invite its friends to a decent dinner on 4 November each year and leave it at that.

There are nevertheless good historical reasons for paying attention to this year's birthday, all of them to do with the present condition of science and with general expectations of it. A century ago, Nature had won a reputation as the champion of Darwinism and of rationality in the explanation of natural phenomena, but had not become a scientific journal in the modern sense. (Even the discovery of the electron still lay ahead.) Instead, the first editor's helpers, people like T. H. Huxley and John Tyndall, wrote their hearts out in telling what excited them in science. Presciently, as it turns out, Nature then as regularly berated the British government for its neglect of science as it does now.

But Nature is no longer a British journal. How could it be when almost 90 per cent of its readers are elsewhere? Indeed, from the start, Nature took the view that science is international, regaling its readers with the agendas of the academy meetings at St Petersburg and Philadelphia as regularly as with those of the Royal Society (of London) and of the Academie des Sciences (of Paris). Nature is now printed once a week at four centres (in Britain, the United States, Tokyo and Beijing) and once a month (as Monthly Nature) in Moscow.

The events of the very recent past can only reinforce that cosmopolitan tendency. All of us know of bright people who have been driven from Russia by repression (or recently, uncertainty) and from India's Indian Institutes of Technology by deprivation, and who are now card-carrying honoured members of the international community. Could even a low-grade 125 th anniversary celebration help to deepen these international connections? (Nature's fondest wish is that there were another name for
"English" — "Esperanto" is bespoken but that it were permissible to write it with a British accent.)

There is another pressure towards the celebration of this anniversary - the gulf that has recently emerged between science and those whom scientists believe should be science's beneficiaries, people at large. The past few decades have, it is true, seen a powerful growth of the health and wealth that people enjoy, much of which is a consequence of science and its many applications. But recent decades have also seen a growth of suspicion of science, especially in the rich countries of the world. (People in India or China, for example, see things very differently.)

Over the years there have been several valiant attempts to change this state of affairs. It is agreed that, in the long run, the solution lies in a more general understanding of the roots of science and also of its role in the remarkable history of this century, now almost past. But that may be too distant a goal. Should not a journal such as this, which benefits so much from its close relationship with the research community, be more directly engaged in helping to give currency to what is now exciting?

These two principles, the international character of science and its role in the general development of society, guide the plans so far devised for celebrating this year's birthday. Mostly the intention is to mark the occasion with a number of events, most of them in the second half of 1994 . The centrepiece will be a conference on the general theme of how our world has evolved, to be held in New York on 31 October and in London on 3 November. We shall of course be as much concerned with physical as with biological evolution; it is hoped that the same people will speak on both occasions. With luck, these events should contribute to the general appreciation of our place in nature.

It is also planned to hold two one-day symposia on the mainland of Europe. The first, in Berlin, will deal with contemporary problems in genetics. The venue has been chosen because of the difficulties encountered in Germany in recent decades with matters such as legislation on genetic manipulation. Can informed discussion help to resolve these, or are they a foretaste of things to come elsewhere?

We also plan a symposium in Paris, later in the year, on the theme of the distinctiveness of science in Europe (where, after all, modern science began). That venue marks the recent resurgence of science in Europe and the part played in that encouraging development by the consistency of French public policies on science over recent decades. Can the rest of Europe follow suit?

We have not forgotten Central Europe and Japan, where there are also tentative schemes that will introduce to audiences there people from elsewhere who may have interesting things to say about contemporary problems. These plans depend on the outcome of discussions with institutions in the regions concerned; details will be published later.

The ambition to make a more direct contribution to the general understanding is best realized by the means that Nature best understands - publication. It is hoped that 1994 will see the realization of a longcherished project to produce a collection of the miscellaneous contents of the issues of Nature over the past 125 years which are a remarkably rich record of the development of modern science.

But that is necessarily a domestic preoccupation. During 1994, Nature will also attempt more deliberately than in the past to foster the spread of intelligence about science and its implications, not so much as a publisher in its own right but in collaboration with others. One objective is to demonstrate that the research community can, by its own efforts, help to make its own intellectual birthright more generally appreciated in the world at large. There are, after all, several routes to understanding.

Explaining the intricacies of, say, the structure of DNA to the world at large may be less effective a reinforcement of the general appreciation than, say, helping to ensure that the significance of DNA is understood within the general culture. But those who battle in the front line for understanding, in the world's classrooms, need more assistance than they are given now. That is another field in which the research community, and Nature in particular, could do more to help.

Further details of these events will be published in the next few weeks, as and when they are decided. Meanwhile, Nature would welcome suggestions from readers who may have other schemes for celebrating an off-season birthday. The guiding principle should be modesty. After all, Nature does not wish to take the wind out of the full-throated celebration there will be 25 years from now.

John Maddox 